\title{
LETTER FROM THE ASSOCIATE EDITOR
}

At least for me, goodbyes are always a mixture of sadness and elation. In this particular case, I am saddened by the fact that JIBS is leaving the University of South Carolina and will no longer be under the skillful and dedicated editorship of David A. Ricks. I am elated by the achievements we helped forge as a result of the advancements made in the field of international business research, the cooperation we received from the officers of the Academy of International Business, the unselfish contributions of time and effort by reviewers, and the willingness of authors to submit their work to the rigors and uncertainties of the review process. I feel that it is safe to say that JIBS not only remains the outstanding refereed professional journal in the field, it has gained far reaching recognition for the quality of the research it now publishes.

My direct association with $J I B S$, first as Managing Editor, and subsequently as Associate Editor, has been a challenging and rewarding experience. I take considerable pride in what has been accomplished during the time that JIBS has been housed at the University of South Carolina. I am both gratified and humbled by the trust that David A. Ricks, and thus the Academy, placed in my judgement, and the opportunities they provided me to serve you, the members of the Academy of International Business.

I do, of course, wish Paul Beamish and his Western Ontario team all the best in the years ahead. I am confident that they will continue to improve on the academic quality and recognition of the journal initiated under the editorship of Ernest W. Ogram, and followed so ably and diligently by William A. Dymsza, and David A. Ricks. The Academy of International Business has been very fortunate to have had all three devote considerable amounts of their time and effort in the pursuit of journalistic excellence.

Brian Toyne 